\title{
Virus-Associated Hemophagocytic Syndrome Caused by Pandemic Swine-Origin Influenza A (H1N1) in a Patient After Unrelated Bone Marrow Transplantation
}

\author{
Akira Katsumi, ${ }^{1,2)}$ Tetsuya Nishida, ${ }^{2,3)}$ Makoto Murata, ${ }^{2)}$ Seitaro Terakura, ${ }^{2)}$ Kazuyuki Shimada, ${ }^{2)}$ \\ Shigeki Saito, ${ }^{2)}$ Miki Kobayashi, ${ }^{1,2)}$ Akari Kodaira, ${ }^{()}$Shinichiro Shibata, ${ }^{(0)}$ Isao Oda, ${ }^{7)}$ Tetsuya Yagi, ${ }^{3)}$ \\ Hitoshi Kiyoi, ${ }^{3)}$ Tadashi Matsushita, $\left.{ }^{4}\right)$ Tetsuhito Kojima, ${ }^{5}$ and Tomoki Naoe ${ }^{2)}$
}

Keywords: virus-associated hemophagocytic syndrome, bone marrow transplantation, H1N1 influenza

\section{To the Editor}

A 55-year-old Asian man was diagnosed as mantle cell lymphoma in 2004. He received conventional chemotherapy followed by autologous peripheral blood stem cell transplantation and achieved complete remission in 2004. The disease relapsed in 2007, and he underwent bone marrow transplantation from an unrelated donor after conditioning with fludarabine $30 \mathrm{mg} / \mathrm{m}^{2}$ once daily i.v. for 5 days (total dose 150 $\mathrm{mg} / \mathrm{m}^{2}$ ) and cyclophosphamide $1 \mathrm{~g} / \mathrm{m}^{2}$ once daily i.v. for 2 days (total dose $2 \mathrm{~g} / \mathrm{m}^{2}$ ). He received tacrolimus and shortterm methotrexate for graft-vs-host disease (GVHD) prophylaxis and achieved complete remission on day 89. On day 663 , at the age of 61 , he was referred to the emergency department of Nagoya University Hospital because of a 2day history of fever and appetite loss. On initial evaluation, he was febrile (temperature : $38.5^{\circ} \mathrm{C}$ ) with a pulse rate of 113 beats/min, blood pressure of $97 / 69 \mathrm{mmHg}$, respiratory rate of 20 breaths/min, and saturation of $88 \%$ at room air. He required $3 \mathrm{~L}$ of supplemental oxygen, which was supplied using a face mask, to maintain an oxygen saturation of $99 \%>\mathrm{A}$ nasopharyngeal swab collected in the emergency department

\footnotetext{
Received: November 10, 2010

Revised : January 31, 2011

Accepted : February 6, 2011

${ }^{1)}$ Division of Transfusion and Cell Therapy, National Center for Geriatrics and Gerontology, Obu, Japan, ${ }^{2)}$ Department of Hematology and Oncology, ${ }^{3)}$ Infectious Diseases, ${ }^{4)}$ Transfusion, and ${ }^{5)}$ Pathophysiological Laboratory Sciences, Nagoya University Graduate School of Medicine, ${ }^{6}$ Nagoya City Public Health Research Institute, and "Showa Health Center, Nagoya, Japan

Address correspondence and reprint request to Akira Katsumi, M.D., Ph.D.

Division of Transfusion and Cell Therapy, National Center for Geriatrics and Gerontology, 35 Gengo, Morioka-cho, Obu 474-8511, Japan

E-mail : katsumi@ncgg.go.jp
}

was negative for influenza A by rapid antigen testing. The patient had been immunized against seasonal influenza, but not against H1N1 influenza.

On arrival at the hematology-oncology department, lymphadenopathy or skin rash was not observed in the patient. He did not take any immunosuppressive agents, having no sign of chronic GVHD at that time. Initial laboratory findings showed a hemoglobin level of $12.4 \mathrm{~g} / \mathrm{dL}$, hematocrit of 35 . $9 \%$, platelet count of $141,000 / \mathrm{mm}^{3}$, and white blood cell (WBC) count of $13,200 / \mathrm{mm}^{3}$ with an absolute neutrophil count of $6,700 / \mathrm{mm}^{3}$. The chemistry profile showed that sodium, potassium, chloride, blood urea nitrogen, creatinine, glucose, asparate aminotransferase (AST), alanine aminotransferase (ALT), and lactate dehydrogenase (LDH) were all within normal limits. The C-reactive protein (CRP) level was $7.6 \mathrm{mg} / \mathrm{dL}$. Serum endotoxin and $\beta$-D glucan were negative. Serum immunoglobulin G, A, M level was 2,242, 27 and 156 $\mathrm{mg} / \mathrm{dL}$, respectively, and maintains the comparable level throughout the course. Soluble interleukin-2 receptor level was $1,360 \mathrm{U} / \mathrm{mL}$. A chest radiograph was normal. A computed tomography scan of the chest was also normal. The patient showed no evidence of recurrence of lymphoma. A blood culture was obtained, and he received a dosage of intravenous imipenem/cilastatin $(0.5 \mathrm{~g} \times 2 /$ day $)$.

On hospital day 9, the patient's clinical condition worsened with progressive dyspnea and hypoxia. The nasopharyngeal swab tested positive for influenza A by rapid antigen testing. A definite diagnosis was based on a positive result for pandemic H1N1 influenza virus by real-time reverse transcription-PCR (RT-PCR) for a nasopharyngeal swab. Oseltamivir $(75 \mathrm{mg} \times 2 /$ day $)$ was started on hospital day 9 . Repeat laboratory data showed pancytopenia with a hemoglobin level of $9.3 \mathrm{~g} / \mathrm{dL}$, hematocrit of $28.1 \%$, platelet count of 
$29,000 / \mathrm{mm}^{3}$, and WBC count of $3,700 / \mathrm{mm}^{3}$ with an absolute neutrophil count of $1,700 / \mathrm{mm}^{3}$. The chemistry profile revealed an AST of $140 \mathrm{IU} / \mathrm{L}, \mathrm{ALT}$ of $69 \mathrm{IU} / \mathrm{L}, \mathrm{LDH}$ of 626 $\mathrm{IU} / \mathrm{L}$, and ferritin level of $3,222 \mathrm{ng} / \mathrm{mL}$. The CRP level was $3.3 \mathrm{mg} / \mathrm{dL}$. Serum endotoxin and $\beta$-D glucan were negative. Coagulation profile revealed prothrombin time of $14.4 \mathrm{~s}$, activated partial thromboplastin time of $42.4 \mathrm{sec}$, and fibrinogen of $422 \mathrm{mg} / \mathrm{dL}$. The FDP and D-dimer level was normal. The triglyceride level was $101 \mathrm{mg} / \mathrm{dL}$. A bone marrow aspiration biopsy revealed mature histiocytes exhibiting hemophagocytosis, suggesting a diagnosis of virus-associated hemophagocytic syndrome (VAHS) (Fig. 1). A high-resolution computed tomography (HRCT) scan of the chest revealed bilateral and peripheral focal ground-glass opacities in the upper, middle, and lower zones that are typical in H1N1 pneumonia (Fig. 2). ${ }^{1,2}$ Multiple blood, urine, and sputum cultures were negative for bacteria and fungi. The patient's cytomegalovirus (CMV) antigenemia was negative. On hospital day 11, the repeat chemistry profile revealed an AST of $542 \mathrm{IU} / \mathrm{L}$, ALT of $388 \mathrm{IU} / \mathrm{L}, \mathrm{LDH}$ of $883 \mathrm{IU} / \mathrm{L}$, and ferritin level of 8,814 $\mathrm{ng} / \mathrm{mL}$. As this patient met the criteria for the diagnosis of VAHS, ${ }^{3}$ empiric treatment was initiated with $1 \mathrm{mg} / \mathrm{kg}$ of prednisolone on day 11, with subsequent reduction in fever. AST, ALT, and LDH levels became normal on hospital days 25,36 , and 25 , respectively. The serum ferritin level decreased to $862 \mathrm{ng} / \mathrm{mL}$ on hospital day 22 . The patient remained in a stable physical condition with a gradual dose reduction of prednisolone.

Pandemic (H1N1) influenza virus first appeared in March 2009 in Mexico and its rapid spread throughout the world marked the beginning of the first influenza pandemic in more than 40 years. ${ }^{4,5}$ VAHS is an unusual disorder characterized by uncontrolled proliferation of mature histiocytes exhibiting hemophagocytosis. ${ }^{3}$ A previous study demonstrated 6 of 68 $(8.8 \%)$ cases of VAHS after allogeneic stem cell

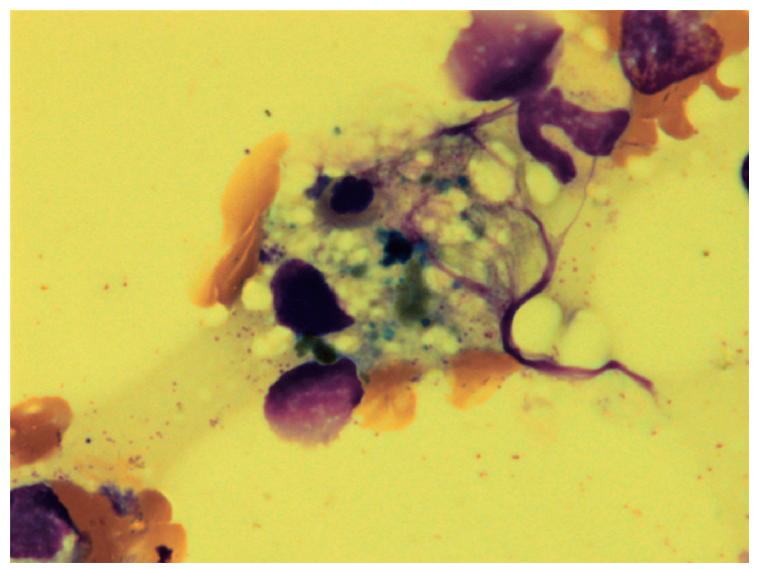

Fig. 1. Bone marrow with May-Giemsa staining showing hemophagocytosis of an erythrocyte and platelets transplantation. ${ }^{6}$ One case was infected with Epstein-Barr virus, 2 cases with CMV, and 3 cases showed no evidence of bacterial, fungal, or viral infections. Previous reports demonstrated VAHS associated with H3N2 seasonal influenza, ${ }^{7,8}$ however, to the best of our knowledge, this patient represents the first report of VAHS associated with H1N1 influenza pneumonia. Physicians taking care of patients with hematologic malignancies should be aware of VAHS as an unusual but potentially severe and life-threatening complication of H1N1 influenza in immunosuppressed individuals. The most
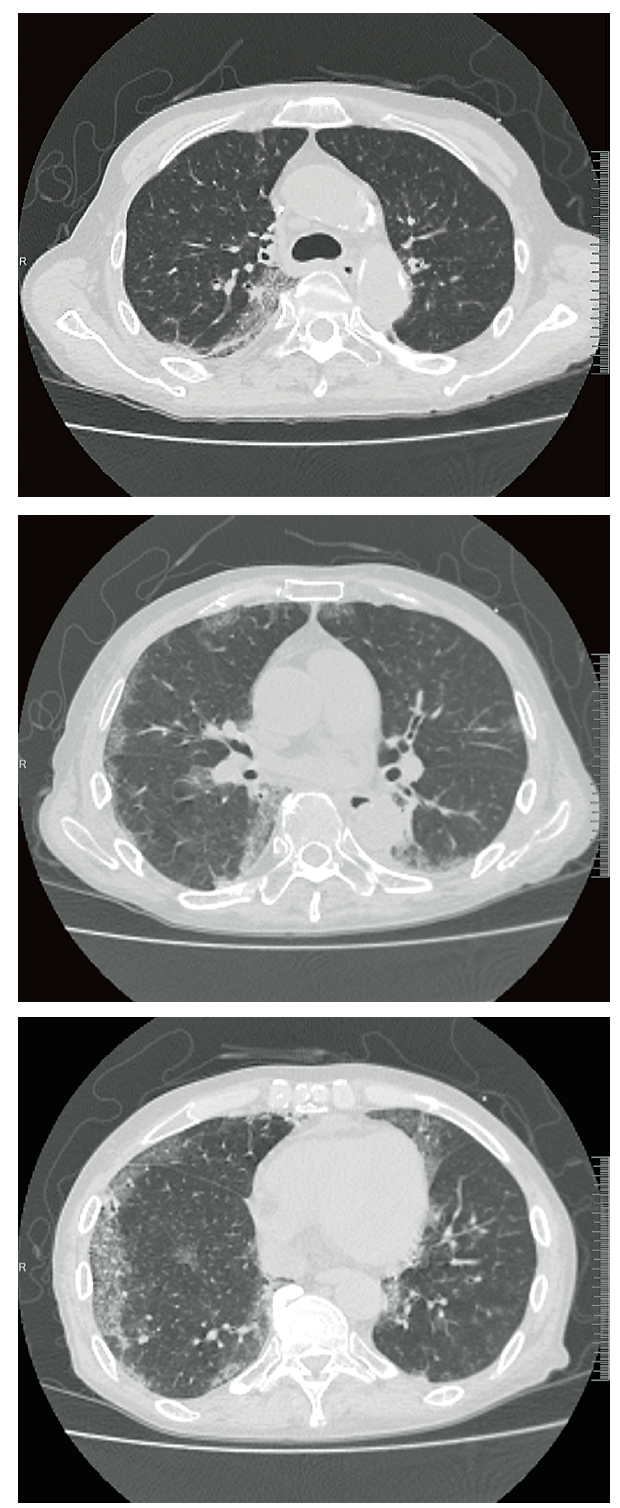

Fig. 2. 61-year-old male patient with $\mathrm{H} 1 \mathrm{~N} 1$ pneumonia. HRCT scan of the chest obtained on hospital day 11 showing bilateral and peripheral focal ground-glass opacities in the upper $(A)$, middle $(B)$, and lower $(C)$ zones. 
common HRCT manifestations of $\mathrm{H} 1 \mathrm{~N} 1$ virus-associated pneumonia are bilateral ground-glass opacities and/or bilateral areas of consolidation, which showed a more severe clinical course. $^{1}$ Early computed tomography may help clinicians recognize incipient cases of $\mathrm{H} 1 \mathrm{~N} 1$ virus-associated pneumonia.

\section{ACKNOWLEDGEMENTS}

This work was supported by grants-in-aid from the Scientific Research of the Ministry of Education, Culture, Sports, Science and Technology (to AK), grants-in-aid for the Longevity Science from the Ministry of Health, Labor and Welfare of Japan (to AK), and Research Grant from Japan Foundation for Aging and Health (to AK).

\section{References}

1 Marchiori E, Zanetti G, Hochhegger B, Rodrigues RS, Fontes CA, et al. : High-resolution computed tomography findings from adult patients with Influenza A (H1N1) virus-associated pneumonia. Eur J Radiol 74:93-98, 2010

2 Agarwal PP, Cinti S, Kazerooni EA: Chest radiographic and CT findings in novel swine-origin influenza A (H1N1) virus (S-OIV) infection. AJR Am J Roentgenol 193:1488-1493, 2009

3 Imashuku S: Differential diagnosis of hemophagocytic syndrome: underlying disorders and selection of the most effective treatment. Int J Hematol 66:135-151, 1997

4 Neumann G, Noda T, Kawaoka Y: Emergence and pandemic potential of swine-origin H1N1 influenza virus. Nature 459:931939, 2009

5 Perez-Padilla R, de la Rosa-Zamboni D, Ponce de Leon S, Hernandez M, Quinones-Falconi F, et al : Pneumonia and respiratory failure from swine-origin influenza A (H1N1) in Mexico. N Engl J Med 361:680-689, 2009

6 Abdelkefi A, Ben Jamil W, Torjman L, Ladeb S, Ksouri H, et al: Hemophagocytic syndrome after hematopoietic stem cell transplantation: a prospective observational study. Int J Hematol 89:368-373, 2009

7 Mou SS, Nakagawa TA, Riemer EC, McLean TW, Hines MH, et al : Hemophagocytic lymphohistiocytosis complicating influenza A infection. Pediatrics 118:e216-219, 2006

8 Potter MN, Foot AB, Oakhill A: Influenza A and the virus associated haemophagocytic syndrome: cluster of three cases in children with acute leukaemia. J Clin Pathol 44:297-299, 1991 